\title{
KOMPARASI METODE AHP DAN SAW DALAM PEMILIHAN KARYAWAN TERBAIK PADA PT. PESTRAP MITRA SUKSES
}

\author{
Nurbayati $^{1}$, Cahyani Budihartanti ${ }^{2}$ \\ ${ }^{1}$ Program Studi Sistem Informasi \\ STMIK Nusa Mandiri Jakarta \\ e-mail: beyo9896@gmail.com \\ ${ }^{2}$ Program Studi Sistem Informasi \\ STMIK Nusa Mandiri Jakarta \\ Nusa Mandiri.ac.id \\ e-mail: cahyani.cbh@nusamandiri.ac.id
}

\begin{abstract}
ABSTRAK
Karyawan memiliki peran yang sangat penting, dalam menentukan keberhasilan dan kesuksesan bagi sebuah perusahaan. Namun Kendala pada PT. Perstrap Mitra Sukses yang merupakan sebuah perusahaan yang bergerak didalam bidang jasa pembasmi hama, masih belum optimal dalam pemilihan karyawan terbaik. Oleh karena itu untuk mempertahankan karyawan yang kompeten perusahaan belum memiliki metode dalam pengambilan keputusan untuk menentukan karyawan terbaik. Untuk mendapatkan hasil yang sesuai dengan kebutuhan, yaitu dengan membuat sistem pengambilan keputusan pemilihan karyawan terbaik dengan menggunakan metode Analytical Hierarcy Process (AHP) merupakan pemilihan penunjang keputusan dalam pembobotan kriteria, bobot dari setiap kriteria bukan ditentukan dari awal tetapi ditentukan menggunakan rumus berdasarkan skala prioritas (tingkat kepentingan) sedangkan metode Simple Additive Weighting (SAW) merupakan metode yang diterapkan dalam penilaian kinerja dimana kriteria yang digunakan dalam penilaian yaitu kualitas kerja, ketrampilan kerja, disiplin kerja, tanggung jawab dan kerjasama. Sistem penunjang keputusan ini merupakan alat bantu yang dapat memberikan solusi dalam membantu menentukan karyawan terbaik secara komputerisasi agar lebih efisen dan efektif. Hasil penelitian membuktikan bahwa aplikasi ini mampu membantu admin dalam penilaian pemilihan proses karyawan terbaik dengan menggunakan metode Analytical Hierarcy Process (AHP) dan metode Simple Additive Weighting (SAW).
\end{abstract}

Kata kunci: Karyawan Terbaik, Sistem Penunjang Keputusan, Analytical Hierarcy Process (AHP), Simple Additive Weighting (SAW)

\begin{abstract}
Employees have a very important role, in determining success and success for a company. However, constraints on PT. Perstrap Mitra Sukses which is a company engaged in the pest-repellent services, still not optimal in the selection of the best employees. Therefore to maintain competent employees of the company has not yet had a method in decision making to determine the best employees. To get a result that suits your needs, by creating the best employee selection decision system using the method of Analytical Hierarcy Process (AHP) is the choice of supporting the decision in weighting criteria, the weight of each criterion is not determined from the beginning but determined using a formula based on the priority scale (level of importance) while the method of Simple Additive Weighting (SAW) is applied, job skills, work discipline, responsibilities and cooperation. This decision-making system is a tool that can provide solutions to help determine the best employees are computerized to be more efisen and effective. The results proved that this application is able to assist admins in the assessment of the selection of the best employee processes using the method of Analytical Hierarcy Process $(A H P)$ and Simple Additive Weighting (SAW) method.
\end{abstract}

Keywords: Best employee, Decision Support system, Analytical Hierarcy Process (AHP), Simple Additive Weighting (SAW)

JISICOM (Journal of Information System, Informatics and Computing)

http://journal.stmikjayakarta.ac.id/index.php/jisicom Telp.+62-21-3905050, e-mail: jisicom@stmikjayakarta.ac.id, jisicom2017@gmail.com 


\section{PENDAHULUAN}

Dalam sebuah perusahaan tenaga kerja atau karyawan mempunyai peranan yang sangat penting, karena merupakan salah satu faktor yang bisa menentukan keberhasilan dan kesuksesan dalam sebuah perusahaan. Karyawan merupakan aset terpenting dalam sebuah perusahaan, karena tanpa karyawan perusahaan tidak akan bertahan lama dan akan mengalami kemunduran [1].

Untuk mendapatkan karyawan yang berkualitas dan kompeten bagian sumber daya manusia (SDM), harus benar-benar melakukan tugasnya dengan baik dengan memilih dan menyaring karyawan sesuai dengan kebutuhan.

Banyak cara yang dilakukan oleh perusahaan untuk mempertahankan karyawan yang kompeten yaitu dengan cara pemberian reward. Pemberian reward dimaksudkan agar karyawan dapat termotivasi dan bekerja dengan lebih baik.

Dalam pemberian reward memerlukan beberapa proses, yaitu dengan cara melakukan penilaian terhadap kinerja karyawan. Dalam melakukan penilaian kinerja karyawan tidak jarang penilaian dilakukan secara subyektif baik yang dilakukan oleh pihak perusahaan maupun pihak yang diberikan kewenangan dalam melakukan penilaian, penilaian secara subyektif dapat terjadi karena adanya suatu hubungan antara karyawan dengan pihak penilai. Penilaian yang dilakukan secara subyektif tentunya dapat menjadi masalah, karena hasil akhir tidak sesuai dengan harapan dan kebutuhan. Penilaian yang bersifat subyektif juga dapat berdampak buruk bagi perusahaan dan menjadi salah satu faktor kemunduran sebuah perusahaan.

PT. Pestrap Mitra Sukses, merupakan sebuah perusahaan yang bergerak didalam bidang jasa pembasmi hama dan telah memiliki banyak pelanggan, banyak karyawan serta teknisi yang ikut berperan dalam mengembangkan perusahaan ini. PT. Pestrap Mitra Sukses belum memiliki metode dalam pengambilan keputusan untuk menentukan karyawan terbaik, untuk menentukan karyawan terbaik masih dilakukan dengan cara konvensional, dimana penilaian lebih cenderung kepada penilaian secara subyektif sehingga tidak efektif. Penilaian pemilihan karyawan terbaik dilakukan dengan tujuan dapat memberikan reward kepada karyawan. Sehingga karyawan dapat lebih termotivasi dalam melaksanakan pekerjaannya dan dapat bekerja lebih baik lagi. Karena dengan memiliki karyawan yang kompeten tentunya akan sangat menguntungkan bagi perusahaan.

Untuk mendapatkan hasil yang sesuai dengan kebutuhan, maka penilaian kinerja karyawan harus dilakukan dengan cara membandingkan sasaran (hasil kerjanya) dengan persyaratan deskripsi pekerjaan yaitu standar pekerjaan yang telah ditetapkan selama periode tertentu [2].

Banyak metode yang dapat diterapkan dalam pengambilan keputusan yang dilakukan dalam penilaian kinerja karyawan agar hasil dapat sesuai dengan kebutuhan. Pengambilan keputusan harus dilakukan secara sistematis, dengan cara mengumpulkan fakta-fakta, kemudian ada penentuan yang matang dari alternatif yang dihadapi, dan selanjutnya mengambil tindakan yang menurut perhitungan merupakan tindakan yang paling tepat [3, pp. 2]. Pada penelitian ini, penulis bermaksud menerapkan metode Analytical Hierarcy Process (AHP) dan metode Simple Additive Weighting (SAW).

Metode Analytical Hierarcy Process (AHP) memiliki keunikan karena dalam pembobotan kriteria, bobot dari setiap kriteria bukan ditentukan dari awal tetapi ditentukan menggunakan rumus berdasarkan skala prioritas (tingkat kepentingan) [4, pp. 57]. Sedangkan metode Simple Additive Weighting (SAW) adalah metode penjumlahan bobot dari kinerja setiap objek-objek yang berbeda dan memiliki kesempatan yang sama pada semua kriteria, metode SAW memerlukan proses normalisasi matriks keputusan ke suatu skala yang dapat dibandingkan dengan semua alternatif yang ada [3, pp. 136].

Penelitian yang dilakukan oleh Munthe dan RMS pada tahun 2018 [5], menjelaskan bahwa pemberian julukan karyawan terbaik dilakukan untuk memacu karyawan untuk berlomba-lomba memberikan pelayanan yang terbaik kepada pelanggan. Metode Analytical Hierarchy Process (AHP) diterapkan dengan menentukan 4 (empat) kriteria yaitu attitude, absensi, kinerja dan masa kerja. Metode AHP diterapkan denan menentukan tingkat prioritas kepentingan setiap kriteria dalam penentuan karyawan terbaik. Hasil akhir penelitian diperoleh karyawan bernama Sri Rahayu terpilih menjadi karyawan terbaik dengan nilai 0.419 atau $41.9 \%$.

Dalam penelitian yang dilakukan oleh Darmawan dan Purwaningsih pada tahun 2019 [6], penelitian dilakukan untuk mengevaluasi kinerja karyawan yang merupakan upaya suatu perusahaan untuk meningkatkan sumber daya manusia, pemberian reward kepada karyawan dengan tujuan untuk

JISICOM (Journal of Information System, Informatics and Computing)

http://journal.stmikjayakarta.ac.id/index.php/jisicom Telp.+62-21-3905050, e-mail:jisicom@stmikjayakarta.ac.id, jisicom2017@gmail.com 


\section{Journal of Information System, Informatics and Computing}

memotivasi karyawan agar bekerja secara maksimal. Metode yang diterapkan dalam penilaian kinerja yaitu dengan metode Simple Additive Weighting (SAW), dimana kriteria yang digunakan dalam penilaian yaitu kualitas kerja, ketrampilan kerja, disiplin kerja, tanggung jawab dan kerjasama. Hasil penilaian dari kriteria tersebut makan akan diperoleh data ternormalisasi (R), dalam hitungan proses hasil akhir dengan perkalian normalisasi $(\mathrm{R})$ dengan bobot nilai dan dijumlahkan sehingga diperoleh nilai terbaik dari hasil perangkingan yang terpilih sebagai alternatif terbaik. Hasil pengolahan data menggunakan SAW terpilih sebagai karyawan terbaik di divisi supporting staff dengan skor 0.880 .

Berdasarkan latar belakang tersebut, maka peneliti mencoba menerapkan metode Analitycal Hierarcy Process (AHP) dan Simple Additive Weigthing (SAW) dalam melakukan penilaian pemilihan karyawan terbaik pada PT. Pestrap Mitra Sukses.

\section{METODE PENELITIAN}

Metode pengumpulan data digunakan untuk mendapatkan data-data, fakta dan informasi yang menunjang penelitian skripsi ini. Metode pengumpulan data yang digunakan dalam penelitian ini adalah sebagai berikut :

\section{a. Observasi}

Dalam penulisan skripsi ini penulis melakukan pengamatan secara langsung hal-hal yang berkaitan dengan proses penentuan karyawan terbaik di PT. Pestrap Mitra Sukses. Dengan melakukan pengamatan penulis dapat mengetahui permasalahan yang ada pada PT. Pestrap Mitra Sukses.

\section{b. Wawancara}

Wawancara adalah proses pengumpulan data kepada manajer dengan mengajukan beberapa pertanyaanpertanyaan secara langsung yang akan membantu dalam pengambilan keputusan pada penelitian ini. Teknik wawancara ini dilakukan dengan melakukan wawancara (interview) dengan narasumber, yaitu Bapak Rinaldy selaku Manajer Pemasaran di PT. Pestrap Mitra Sukses yang mengetahui tentang kriteria-kriteria untuk menentukan pemilihan pegawai terbaik di PT. Pestrap Mitra Sukses.

\section{c. Studi Pustaka}

Kegiatan ini dilakukan dengan cara mengumpulkan summber referensi sebagai acuan seperti buku, jurnal dan artikel-artikel atau referensi-referensi yang ada terkait dengan penelitian.

menggunakan font antara ukuran 8-11pt untuk Tabel dan Gambar.

\section{HASIL DAN PEMBAHASAN}

\subsection{Perhitungan dengan metode AHP (Analytical Hierarchy Process)}

Dalam membangun sistem pendukung keputusan ini berdasarkan penilaian karyawan yang diberikan manager pada PT. Pestrap Mitra Sukses. Dimana dalam penilaian ini setiap karyawan dinilai berdasarkan kriteria yang telah ditentukan. PT. Pestrap Mitra Sukses telah menentukan beberapa kriteria yaitu kehadiran/absensi, performa kerja, jadwal pest control, dan berdasarkan kriteria yang ada maka akan dilakukan perbandingan berpasangan (pairwise comparison) antara kriteria. Sehingga akan diperoleh nilai untuk masing-masing kriteria. Dalam proses perhitungan ini menggunakan Microsoft Excel 2013, dan diambil 5 sampel alternatif kemudian akan dilakukan perbandigan berpasangan (pairwise comparison) antara alternatif dengan kriteria masingmasing yang akan dilakukan dengan metode AHP (Analytical Hierarchy Process). Hasil akhir akan di dapat perangkingan untuk karyawan pada PT.Pestrap Mitra Sukses.

\subsubsection{Matriks perbandingan berpasangan (pairwise comparison)}

Pada tahap ini membuat perbandingan elemen secara berpasangan sesuai dengan kriteria dan altermatif yang telah ditentukan. maka didapat tabel matriks perbandingan antar kriteria dan matriks perbandingan antar alternatif.

1. Matriks Perbandingan berpasangan kriteria

Pada Tabel 1, ditampilkan matriks perbandingan berpasangan kriteria.

Tabel 1. Matriks Perbandingan Berpasangan Kriteria

\begin{tabular}{|l|c|c|c|}
\hline \multicolumn{4}{|c|}{ Matriks perbandingan Kriteria } \\
\hline Kriteria & $\begin{array}{c}\text { Kehadira } \\
\text { n/absensi }\end{array}$ & $\begin{array}{c}\text { Performa } \\
\text { kerja }\end{array}$ & $\begin{array}{c}\text { Jadwal } \\
\text { pest } \\
\text { control }\end{array}$ \\
\hline $\begin{array}{l}\text { Kehadiran/ } \\
\text { absensi }\end{array}$ & 1 & 4 & 4 \\
\hline $\begin{array}{l}\text { Performa } \\
\text { kerja }\end{array}$ & 0.25 & 1 & 2 \\
\hline
\end{tabular}




\section{Journal of Information System, Informatics and Computing}

\begin{tabular}{|l|c|c|c|}
\hline $\begin{array}{l}\text { Jadwal pest } \\
\text { control }\end{array}$ & 0.25 & 0.50 & 1 \\
\hline Jumlah & 1.50 & 5.50 & 7 \\
\hline
\end{tabular}

Sumber : Olah Data (2020)

2. Matriks perbandingan berpasangan alternatif kehadiran

Pada Tabel 2, ditampilkan matriks perbandingan berpasangan alternatif kahadiran.

Tabel 2. Matriks Perbandingan Berpasangan Alternatif Kehadiran

\begin{tabular}{|c|c|c|c|c|c|}
\hline \multicolumn{7}{|c|}{ Matriks Perbandingan Alternatif } \\
\hline Kehadiran & Toto & Untung & Wahyu & Maman & Asep \\
\hline Toto & 1 & 0.2 & 2 & 3 & 2 \\
\hline Untung & 5 & 1 & 3 & 6 & 2 \\
\hline Wahyu & 0.5 & 0.3333 & 1 & 2 & 0.3333 \\
\hline Maman & 0.3333 & 0.1666 & 0.5 & 1 & 0.3333 \\
\hline Asep & 0.5 & 0.5 & 3 & 3 & 1 \\
\hline Jumlah & 7.3333 & 2.2 & 9.5 & 15 & 5.6666 \\
\hline
\end{tabular}

Sumber : Olah Data (2020)

\begin{tabular}{|c|c|c|c|c|c|}
\hline Untung & 0.25 & 1 & 0.3333 & 0.5 & 2 \\
\hline Wahyu & 0.25 & 3 & 1 & 2 & 2 \\
\hline Maman & 0.25 & 2 & 0.5 & 1 & 0.5 \\
\hline Asep & 0.25 & 0.25 & 0.5 & 2 & 1 \\
\hline Jumlah & 2 & 10.25 & 6.3333 & 9.5 & 9.5 \\
\hline
\end{tabular}

Sumber: Olah Data (2020)

3. Matriks perbandingan berpasangan alternatif performa kerja

Pada Tabel 3 ditampilkan matriks perbandingan berpasangan alternatif performa kerja

Tabel 3. Matriks Perbandingan Berpasangan Alternatif Performa Kerja

\begin{tabular}{|c|c|c|c|c|c|}
\hline \multicolumn{7}{|c|}{ Matriks perbandingan alternatif } \\
\hline $\begin{array}{c}\text { Performa } \\
\text { Kerja }\end{array}$ & Toto & Untung & Wahyu & Maman & Asep \\
\hline Toto & 1 & 4 & 4 & 4 & 4 \\
\hline Untung & 0.25 & 1 & 0.3333 & 0.5 & 2 \\
\hline Wahyu & 0.25 & 3 & 1 & 2 & 2 \\
\hline Maman & 0.25 & 2 & 0.5 & 1 & 0.5 \\
\hline Asep & 0.25 & 0.25 & 0.5 & 2 & 1 \\
\hline Jumlah & 2 & 10.25 & 6.3333 & 9.5 & 9.5 \\
\hline
\end{tabular}

Sumber: Olah Data (2020)

4. Matriks perbandingan berpasangan alternatif Jadwal pest control

Pada Tabel 4, ditampilkan Matriks perbandingan berpasangan alternatif Jadwal pest control

Tabel 4. Matriks Perbandingan Berpasangan Alternatif Jadwal Pest Control

Matriks perbandingan alternatif

\begin{tabular}{|l|c|c|c|c|c|}
\hline $\begin{array}{c}\text { Jadwal } \\
\text { Pest } \\
\text { Control }\end{array}$ & Toto & Untung & Wahyu & Maman & Asep \\
\hline Toto & 1 & 0.3333 & 2 & 3 & 2 \\
\hline Untung & 3 & 1 & 3 & 5 & 3 \\
\hline Wahyu & 0.5 & 0.3333 & 1 & 4 & 0.3333 \\
\hline Maman & 0.3333 & 0.2 & 0.25 & 1 & 0.5 \\
\hline Asep & 0.5 & 0.3333 & 3 & 2 & 1 \\
\hline Jumlah & 5.3333 & 2.2 & 9.25 & 15 & 6.8333 \\
\hline
\end{tabular}

Sumber : Olah Data (2020)

\subsubsection{Sintesis}

Pada proses sintesis ini dengan cara menjumlahkan nilai-nilai dari setiap kolom pada tabel matriks perbandingan berpasangan. Membagi setiap nilai dari kolom dengan jumlah kolom yang bersangkutan untuk memperoleh normalisasi matriks. Selanjutnya menjumlahkan nilai-nilai dari setiap baris dan membaginya dengan jumlah elemen untuk mendapatkan nilai rata-rata.

Tabel 5. Proses Sintesis Antar Kriteria

\begin{tabular}{|l|c|c|c|c|c|}
\hline \multicolumn{1}{|c|}{ Kriteria } & $\begin{array}{c}\text { Kehadiran/ } \\
\text { absensi }\end{array}$ & $\begin{array}{c}\text { Performa } \\
\text { kerja }\end{array}$ & $\begin{array}{c}\text { Jadwal pest } \\
\text { control }\end{array}$ & jumlah & Rata-rata \\
\hline $\begin{array}{l}\text { Kehadiran/ } \\
\text { absensi }\end{array}$ & 0.66666 & 0.72727 & 0.571428 & 1.96536 & 0.65512 \\
\hline $\begin{array}{l}\text { Performa } \\
\text { kerja }\end{array}$ & 0.16666 & 0.18181 & 0.28571 & 0.63419 & 0.21139 \\
\hline $\begin{array}{l}\text { Jadwal pest } \\
\text { control }\end{array}$ & 0.16666 & 0.09090 & 0.14285 & 0.40043 & 0.13347 \\
\hline jumlah & & & & & 1.00 \\
\hline
\end{tabular}

Sumber : Olah Data (2020)

Berdasarkan Tabel 5, maka didapat nilai ratarata masing-masing kriteria kehadiran/absensi bernilai 0.65512 , performa kerja bernilai 0.21139 dan untuk jadwal pest control bernilai 0.13347 . Dari hasil perhitungan tersebut di dapat kriteria yang memiliki tingatan terpenting yaitu kehadiran/absensi selanjutnya performa kerja dan terakhir jadwal pest control.

Tabel 6. Proses Sintesis Kriteria Antara Alternatif Kehadiran

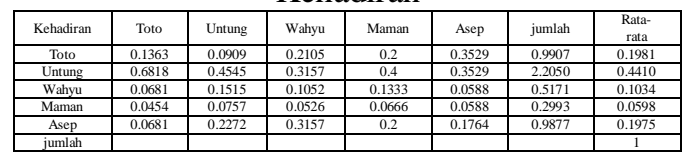

Sumber : Olah Data (2020)

Berdasarkan tabel diatas maka didapat nilai rata-rata masing-masing alternatif terhadap kriteria kehadiran/absensi untuk Toto bernilai 0.1981, Untung bernilai 0.4410, Wahyu bernilai 0.1034, Maman bernilai 0,0598 sedangkan untuk Asep bernilai 0.1975

JISICOM (Journal of Information System, Informatics and Computing)

http://journal.stmikjayakarta.ac.id/index.php/jisicom Telp.+62-21-3905050, e-mail:jisicom@stmikjayakarta.ac.id, jisicom2017@gmail.com 


\section{Journal of Information System, Informatics and Computing}

. Dari hasil perhitungan tersebut di dapat nilai yang memiliki tingkatan terpenting atau tertinggi yaitu Untung.

Tabel 7. Proses Sintesis Kriteria Antara Alternatif Perfrorma Kerja

\begin{tabular}{|l|c|c|c|c|c|c|c|}
\hline $\begin{array}{c}\text { Performa } \\
\text { kerja }\end{array}$ & Toto & Untung & Wahyu & Maman & Asep & Jumlah & Rata-Rata \\
\hline Toto & 0.5 & 0.3902 & 0.6315 & 0.4210 & 0.4210 & 2.3639 & 0.4727 \\
\hline Untung & 0.125 & 0.0975 & 0.0526 & 0.0526 & 0.2105 & 0.5383 & 0.1076 \\
\hline Wahyu & 0.125 & 0.2926 & 0.1578 & 0.2105 & 0.2105 & 0.9966 & 0.1993 \\
\hline Maman & 0.125 & 0.1951 & 0.0789 & 0.1052 & 0.0526 & 0.5569 & 0.1113 \\
\hline Asep & 0.125 & 0.0243 & 0.0789 & 0.2105 & 0.1052 & 0.5441 & 0.1088 \\
\hline jumlah & & & & & & & 1 \\
\hline
\end{tabular}

Sumber : Olah Data (2020)

Berdasarkan tabel diatas maka didapat nilai rata-rata masing-masing alternatif terhadap kriteria performa kerja untuk Toto bernilai 0.4727 , Untung bernilai 0.1076, Wahyu bernilai 0.1993, Maman bernilai 0,1113 sedangkan untuk Asep bernilai 0.1088 . Dari hasil perhitungan tersebut di dapat nilai yang memiliki tingkatan terpenting atau tertinggi yaitu Toto.

Tabel 8. Proses Sintesis Kriteria Antara Alternatif Jadwal Pest Control

\begin{tabular}{|c|c|c|c|c|c|c|c|}
\hline $\begin{array}{c}\text { Jadwal } \\
\text { Pest } \\
\text { Control }\end{array}$ & Toto & Untung & Wahyu & Maman & Asep & $\begin{array}{c}\text { Jumla } \\
\mathrm{h}\end{array}$ & $\begin{array}{l}\text { Rata- } \\
\text { Rata } \\
\end{array}$ \\
\hline Toto & 0.1875 & 0.1515 & 0.2162 & 0.2 & 0.2926 & $\begin{array}{l}1.047 \\
4\end{array}$ & 0.209 \\
\hline Untung & 0.5625 & 0.4545 & 0.3243 & 0.3333 & 0.4390 & 2.113 & 0.422 \\
\hline Wahyu & 0.9375 & 0.1515 & 0.1081 & 0.2666 & 0.0487 & $\frac{1}{0.668}$ & $\frac{1}{0.133}$ \\
\hline Maman & 0.0625 & 0.0909 & 0.0270 & 0.0666 & 0.0731 & 0.320 & 0.064 \\
\hline Asep & 0.0937 & 0.1515 & 0.3243 & 0.1333 & 0.1463 & 0.849 & 0.169 \\
\hline Jumlah & & & & & & & \\
\hline
\end{tabular}

Sumber : Olah Data (2020)

Berdasarkan tabel diatas maka didapat nilai rata-rata masing-masing alternatif terhadap kriteria jadwal pest control untuk Toto bernilai 0.2095 , Untung bernilai 0.4227 , Wahyu bernilai 0.1337 , Maman bernilai 0,0640 sedangkan untuk Asep bernilai 0.1698 . Dari hasil perhitungan tersebut di dapat nilai yang memiliki tingkatan terpenting atau tertinggi yaitu Untung.

\subsubsection{Menetukan nilai CI (Consistency Index) dan CR (Consistency Random)}

Penilaian terhadap perbandingan dianggap konsisten dengan ketentuan jika nilai CR (Consistency Random) tidak lebih dari 0,1 sehingga penilaian perbandingan kriteria penentuan karyawan terbaik sudah konsisten. Sebelum menentukan nilai CI dan CR harus terlebih dahalu menentukan nilai Lamda max. a. Menentukan nilai CI dan CR antar kriteria

$$
\begin{aligned}
& \lambda \max =(1.50 * 0.655122655) \\
& +(5.50 * 0.211399711)+(7 \\
& \text { * } 0.133477633 \\
& =3.07972583 \\
& C I=\frac{(\lambda \text { maks }-\mathrm{n})}{\mathrm{n}-1} \\
& =\frac{(3.07972584-3)}{3-1} \\
& =0.039862915 \\
& C R=\frac{C I}{R I} \\
& =\frac{0.039862915}{1.12} \\
& =0.068729164
\end{aligned}
$$

Berdasarkan perhitungan di atas didapat nilai untuk CR sebesar 0.068729164 maka penilaian perbandingan dianggap kosisten karena CR tidak lebih dari 0.1 .

b. Menentukan nilai CI dan CR alternatif kehadiran/absensi

$$
\begin{aligned}
& =5.423261 \\
C I & =\frac{(\lambda \text { maks }-\mathrm{n})}{\mathrm{n}-1} \\
& =\frac{(5.423261-3)}{3-1} \\
& =0.1058153 \\
C R & =\frac{C I}{R I} \\
= & \frac{0.1058153}{1.12}
\end{aligned}
$$$$
\lambda \max =(7.3333333 * 0.198148)+(2.2
$$$$
* 0.4410189)+(9.5
$$$$
* 0.1034234)+(15
$$$$
* 0.0598668)+(5.666667
$$$$
\text { * 0.1975429) }
$$

JISICOM (Journal of Information System, Informatics and Computing) http://journal.stmikjayakarta.ac.id/index.php/jisicom Telp.+62-21-3905050, e-mail:jisicom@stmikjayakarta.ac.id, jisicom2017@gmail.com 


\section{Journal of Information System, Informatics and Computing}

$$
=0.0944779
$$

Berdasarkan perhitungan di atas didapat nilai untuk CR sebersar 0.0944 maka penilaian perbandingan dianggap kosisten karena CR tidak lebih dari 0.1 .

c. Menentukan nilai CI dan CR performa kerja

$$
\begin{aligned}
& \lambda \max =(2 * 0,4727856)+(10,25 * 0,1076701) \\
& +(6,3333 * 0,1993261+(9,5 \\
& * 0,1113928)+(9,5 * 0,1088254) \\
& =5,4036612 \text { ) } \\
& C I=\frac{(\lambda \text { maks }-\mathrm{n})}{\mathrm{n}-1} \\
& =\frac{(5.4036612-3}{3-1} \\
& =0.1009153 \\
& C R=\frac{C I}{R I} \\
& =\frac{(0.1009153)}{1.12} \\
& =0.0901029
\end{aligned}
$$

Berdasarkan perhitungan di atas didapat nilai untuk CR sebersar 0.0901 maka penilaian perbandingan dianggap kosisten karena CR tidak lebih dari 0.1 .

d. Menentukan nilai CI dan CR jadwal pest control

$$
\begin{aligned}
& \lambda \max =(5,33333 * 0,2095829)+(2,2 * \\
& 4227455)+(9,25 * 0,1337641)+(15 * \\
& 0,0640547)+(6,8333 * 0,1698529) \\
& =5,4066148 \\
& C I=\frac{(\lambda \text { maks }-\mathrm{n})}{\mathrm{n}-1} \\
& =\frac{(5.4066148-3}{3-1} \\
& =0.1016537 \\
& C R=\frac{C I}{R I}
\end{aligned}
$$

$$
\begin{aligned}
& =\frac{0.1016537}{1.12} \\
& =0.0907622
\end{aligned}
$$

Berdasarkan perhitungan di atas didapat nilai untuk CR sebesar 0.0907 maka penilaian perbandingan dianggap kosisten karena CR tidak lebih dari 0.1 .

\subsubsection{Proses Perangkingan}

Dari seluruh proses tahapan diatas, selanjutnya proses perankingan adalah dengan cara mengalikan nilai rata-rata kategori dengan nilai ratarata alternatif terhadap kategori maka akan di dapat nilai pada tabel berikut ini:

Tabel 9. Proses Perangkingan

\begin{tabular}{|l|c|c|}
\hline \multicolumn{1}{|c|}{ Alternatif } & Jumlah & Rangking \\
\hline Toto & 0.2577 & 2 \\
\hline Untung & 0.3681 & 1 \\
\hline Wahyu & 0.1277 & 4 \\
\hline Maman & 0.0713 & 5 \\
\hline Asep & 0.1750 & 3 \\
\hline Jumlah & 1 & \\
\hline
\end{tabular}

Sumber : Olah Data (2020)

Berdasarkan tabel diatas alternatif yang memiliki tingkatan terpenting yaitu Untung dengan nilai 0,3681 , selanjutnya Toto dengan nilai 0,2577 , Asep bernilai 0,1750, Wahyu dengan nilai 0,1277 dan posisi terakhir yaitu Maman degan nilai 0,0713.

\subsection{Perhitungan Dengan Metode SAW (Simple Additive Weighting)}

\subsubsection{Pembobotan pada kriteria}

Pada proses ini dilakukan pembobotan dari masing-masing kriteria yang telah ditentukan, terdapat tiga kriteria diantaranya kehadiaran atau absensi, performa kerja dan jadwal pest control berikut nila bobot dari masing masing kriteria yang telah penulis susun dalam tabel sebagai berikut:

a. Pembobotan pada kriteria

Pembobotan untuk kriteria dapat dilihat pada Tabel 10

Tabel 10. Pembobotan Kehadiran atau Absensi

JISICOM (Journal of Information System, Informatics and Computing) http://journal.stmikjayakarta.ac.id/index.php/jisicom Telp.+62-21-3905050, e-mail:jisicom@stmikjayakarta.ac.id, jisicom2017@gmail.com 


\section{Journal of Information System, Informatics and Computing}

\begin{tabular}{|l|c|c|}
\hline \multicolumn{1}{|c|}{ Kriteria } & Kategori & Bobot \\
\hline $\begin{array}{l}\text { Kehadiran/ } \\
\text { Absensi }\end{array}$ & Benefit & 0.6551 \\
\hline Performa Kerja & Benefit & 0.2113 \\
\hline $\begin{array}{l}\text { Jadwal Pest } \\
\text { Control }\end{array}$ & Benefit & 0.13347 \\
\hline
\end{tabular}

Sumber : Olah Data (2020)

\section{b. Kehadiran atau Absensi}

Pembobotan untuk kategori kehadiran atau absensi dapat dilihat pada Tabel 11

Tabel 11. Pembobotan Kehadiran atau Absensi

\begin{tabular}{|c|c|c|}
\hline Kriteria & Range & Bobot \\
\hline \multirow{4}{*}{ Kehadiran/Absensi } & $25-26$ & 1 \\
\cline { 2 - 3 } & $23-24$ & 0.9 \\
\cline { 2 - 3 } & $21-22$ & 0.8 \\
\cline { 2 - 3 } & $19-20$ & 0.7 \\
\cline { 2 - 3 } & $17-18$ & 0.6 \\
\hline
\end{tabular}

Sumber : Olah Data (2020)

c. Performa Kerja

Pembobotan untuk kategori performa kerja dapat dilihat pada Tabel 12

Tabel 12. Pembobotan Performa Kerja

\begin{tabular}{|c|c|c|}
\hline Kriteria & Range & Bobot \\
\hline \multirow{4}{*}{ Performa Kerja } & 100 & 1 \\
\cline { 2 - 3 } & 90 & 0.9 \\
\cline { 2 - 3 } & 80 & 0.8 \\
\cline { 2 - 3 } & 70 & 0.7 \\
\cline { 2 - 3 } & 60 & 0.6 \\
\hline
\end{tabular}

Sumber : Olah Data (2020)

d. Jadwal Pest Control

Pembobotan untuk kategori jadwal pest control dapat dilihat pada Tabel 13

Tabel 13. Pembobotan Performa Kerja

\begin{tabular}{|l|c|c|}
\hline Kriteria & Range & Bobot \\
\hline \multirow{4}{*}{$\begin{array}{l}\text { Jadwal Pest } \\
\text { Control }\end{array}$} & $25-26$ & 1 \\
\cline { 2 - 3 } & $23-24$ & 0.9 \\
\cline { 2 - 3 } & $21-22$ & 0.8 \\
\cline { 2 - 3 } & $19-20$ & 0.7 \\
\cline { 2 - 3 } & $17-18$ & 0.6 \\
\hline
\end{tabular}

Sumber : Olah Data (2020)

\subsubsection{Mentukan Nilai Matriks Normalisasi Berdasarkan Kriteria}

Dalam menentukan karyawan terbaik penulis mengambil 5(lima) karyawan sebagai contoh untuk penerapannya dengan menggunakan metode SAW (Simple Additive Weight). Sebelum menentukan nilai matriks normalisasi, terlebih dahulu menentukan nilai alternatif terhadap kriteria selanjutnya menentukan rating kecocokan. Setiap alternatif diberi nilai terhadap katergori dengan bobot yang berbeda antar alternatif dapat dilihat pada tabel IV.14 yang terdapat lima alternatif dan tiga kriteria. Selanjutnya menentukan rating kecocokan dapat dilihat pada tabel IV.15 dimana pada tabel ini nilai antar masing-masing alternatif di sesuaikan dengan pembobotan yang telah ditentukan.

\section{a. Menentukan Nilai Alternatif Terhadap Kriteria}

Tabel 14. Nilai Alternatif Terhadap Kriteria

\begin{tabular}{|c|l|c|c|c|}
\hline No & Alternative & $\begin{array}{c}\text { Kehadiran/ } \\
\text { Absensi }\end{array}$ & $\begin{array}{c}\text { Performa } \\
\text { Kerja }\end{array}$ & $\begin{array}{c}\text { Jadwal } \\
\text { Pest } \\
\text { Control }\end{array}$ \\
\hline 1 & Toto & $23-24$ & 80 & $23-24$ \\
\hline 2 & Untung & $25-26$ & 90 & $25-26$ \\
\hline 3 & Wahyu & $21-22$ & 70 & $21-22$ \\
\hline 4 & Maman & $19-20$ & 80 & $19-20$ \\
\hline 5 & Asep & $23-24$ & 70 & $23-24$ \\
\hline
\end{tabular}

Sumber : Olah Data (2020)

b. Menentukan Rating Kecocokan

Pada proses menentukan rating kecocokan maka nilai dari masing-masing alternatif pada Tabel 14 disesuaikan dengan pembobotan dari setiap kriteria yang telah ditentukan, maka rating kecocokan dapat dilihat pada Tabel 15 .

Tabel 15. Rating Kecocokan

\begin{tabular}{|c|l|c|c|c|}
\hline No & Alternative & $\begin{array}{c}\text { Kehadiran// } \\
\text { Absensi }\end{array}$ & $\begin{array}{c}\text { Performa } \\
\text { Kerja }\end{array}$ & $\begin{array}{c}\text { Jadwal Pest } \\
\text { Control }\end{array}$ \\
\hline 1 & Toto & 0.9 & 0.8 & 0.9 \\
\hline 2 & Untung & 1 & 0.8 & 1 \\
\hline 3 & Wahyu & 0.8 & 0.7 & 0.8 \\
\hline 4 & Maman & 0.7 & 0.8 & 0.7 \\
\hline 5 & Asep & 0.9 & 0.7 & 0.9 \\
\hline
\end{tabular}

Sumber : Olah Data (2020)

c. Menentukan Matriks Normalisasi

Pada tahap matriks normalisasi harus menghitung berdasarkan atribut yang telah ditentukan, untuk kasus ini penulis telah menentukan atribut yang digunakaan yaitu keuntungan atau benefit dimana nilai terbesar adalah nilai yang terbaik. Berikut hasil perhitung dengan rumus sebagai berikut: 


\section{Journal of Information System, Informatics and Computing}

$$
r i j\left\{\left[\begin{array}{c}
\frac{x i j}{\operatorname{maxi} x i j} \\
\frac{\min x i j}{x i j}
\end{array}\right]\right\}
$$

Keterangan $=$ Jika $\mathrm{j}$ adalah atribut keuntungan (benefit)

$=$ Jika $\mathrm{j}$ adalah atribut biaya (cost)

Matriks Normalisasi Untuk Baris Ke 1-5 Pada Kolom Ke-1 Kriteria Kehadiran

$$
\begin{aligned}
& r 11=\frac{0,9}{\max (0.9,1,0,8,0,7,0,9)}=\frac{0,9}{1}=0,9 \\
& r 21=\frac{1}{\max (0,91,0,8,0,7,0,9)}=\frac{1}{1}=1 \\
& r 31=\frac{1}{\max (0,9,1,0,8,0,7,0,9)}=\frac{0,8}{1}=0,8 \\
& r 41=\frac{0,7}{\max (0,9,1,0,8,0,7,0,9)}=\frac{0,7}{1}=0,7 \\
& r 51=\frac{0,9}{\max (0,9,1,0,8,0,7,0,9)}=\frac{0,9}{1}=0,9
\end{aligned}
$$

Matriks Normalisasi Untuk Baris Ke 1-5 Pada Kolom Ke-1 Kriteria Kehadiran

$$
\begin{aligned}
& r 11=\frac{9}{\max (0,9,1,0,8,0,7,0,9)}=\frac{0,9}{1}=0,9 \\
& r 21=\frac{1}{\max (0,9,1,0,8,0,7,0,9)}=\frac{1}{1}=1 \\
& r 31=\frac{1}{\max (0,9,1,0,8,0,7,0,9)}=\frac{0,8}{1}=0,8 \\
& r 41=\frac{0,7}{\max (0,9,1,0,8,0,7,0,9)}=\frac{0,7}{1}=0,7 \\
& r 51=\frac{0,9}{\max (0,9,1,0,8,0,7,0,9)}=\frac{0,9}{1}=0,9
\end{aligned}
$$

Matriks Normalisasi Untuk Baris Ke 15.Pada Kolom Ke-1 Kriteria Kehadiran

$$
\begin{aligned}
& r 11=\frac{0,9}{\max (0,9,1,0,8,0,7,0,9)}=\frac{0,9}{1}=0,9 \\
& r 21=\frac{1}{\max (0,9,1,0,8,0,7,0,9)}=\frac{1}{1}=1 \\
& r 31=\frac{0,8}{\max (0,9,1,0,8,0,7,0,9)}=\frac{0,8}{1}=0,8 \\
& r 41=\frac{0,7}{\max (0,9,1,0,8,0,7,0,9)}=\frac{0,7}{1}=0,7
\end{aligned}
$$

$r 51=\frac{0,9}{\max (0,9,1,0,8,0,7,0,9)}=\frac{0,9}{1}=0,9$

Matriks Normalisasi Untuk Baris Ke 1-5 Pada Kolom Ke-1 Kriteria Kehadiran

$$
\begin{aligned}
& r 11=\frac{0,9}{\max (0,9,1,0,8,0,7,0,9)}=\frac{0,9}{1}=0,9 \\
& r 21=\frac{1}{\max (0,9,1,0,8,0,7,0,9)}=\frac{1}{1}=1 \\
& r 31=\frac{0,8}{\max (0,9,1,0,8,0,7,0,9)}=\frac{0,8}{1}=0,8 \\
& r 41=\frac{0,7}{\max (0,9,1,0,8,0,7,0,9)}=\frac{0,7}{1}=0,7 \\
& r 51=\frac{0,9}{\max (0,9,1,0,8,0,7,0,9)}=\frac{0,9}{1}=0,9
\end{aligned}
$$

Matriks Normalisasi Untuk Baris Ke 1-5 Pada Kolom Ke-1 Kriteria Kehadiran

$$
\begin{aligned}
& r 11=\frac{0,9}{\max (0,9,1,0,8,0,7,0,9)}=\frac{0,9}{1}=0,9 \\
& r 21=\frac{1}{\max (0,9,1,0,8,0,7,0,9)}=\frac{1}{1}=1 \\
& r 31=\frac{0,8}{\max (0,9,1,0,8,0,7,0,9)}=\frac{0,8}{1}=0,8 \\
& r 41=\frac{0,7}{\max (0,9,1,0,8,0,7,0,9)}=\frac{0,7}{1}=0,7 \\
& r 51=\frac{0,9}{\max (0,9,1,0,8,0,7,0,9)}=\frac{0,9}{1}=0,9
\end{aligned}
$$

Matriks Normalisasi Untuk Baris Ke 1-5 Pada Kolom Ke-2 Kriteria Performa Kerja

$$
\begin{aligned}
& r 12=\frac{0,8}{\max (0,8,0,8,0,7,0,8,07)}=\frac{0,8}{0,8}=1 \\
& r 22=\frac{0,8}{\max (0,8,0,8,0,7,0,8,07)}=\frac{0,8}{0,8}=1 \\
& r 32=\frac{0,7}{\max (0,8,0,8,0,7,0,8,07)}=\frac{0,7}{0,8}=0,875 \\
& r 42=\frac{0,8}{\max (0,8,0,8,0,7,0,8,07)}=\frac{0,8}{0,8}=1 \\
& r 52=\frac{0,7}{\max (0,8,0,8,0,7,0,8,07)}=\frac{0,7}{0,8}=0,875
\end{aligned}
$$

Matriks Normalisasi Untuk Baris Ke 1-5 Pada Kolom Ke-2 Kriteriaa Performa Kerja 


\section{Journal of Information System, Informatics and Computing}

$$
\begin{aligned}
& r 12=\frac{0,8}{\max (0,8,0,8,0,7,0,8,07)}=\frac{0,8}{0,8}=1 \\
& r 22=\frac{0,8}{\max (0,8,0,8,0,7,0,8,07)}=\frac{0,8}{0,8}=1 \\
& r 32=\frac{0,7}{\max (0,8,0,8,0,7,0,8,07)}=\frac{0,7}{0,8}=0,875 \\
& r 42=\frac{0,8}{\max (0,8,0,8,0,7,0,8,07)}=\frac{0,8}{0,8}=1 \\
& r 52=\frac{0,7}{\max (0,8,0,8,0,7,0,8,07)}=\frac{0,7}{0,8}=0,875
\end{aligned}
$$

Matriks Normalisasi Untuk Baris Ke 1-5 Pada Kolom Ke-3 Jadwal Pest Control

$$
\begin{aligned}
& r 13=\frac{0,9}{\max (0,9,1,0,8,0,7,0,9)}=\frac{0,9}{1}=0,9 \\
& r 23=\frac{1}{\max (0,9,1,0,8,0,7,0,9)}=\frac{1}{1}=1 \\
& r 33=\frac{0,8}{\max (0,9,1,0,8,0,7,0,9)}=\frac{0,8}{1}=0,8 \\
& r 43=\frac{0,7}{\max (0,9,1,0,8,0,7,0,9)}=\frac{0,7}{1}=0,7 \\
& r 53=\frac{0,9}{\max (0,9,1,0,8,0,7,0,9)}=\frac{0,9}{1}=0,9
\end{aligned}
$$

\begin{tabular}{|c|c|c|c|c|}
\hline $\begin{array}{l}\mathrm{N} \\
\mathrm{o}\end{array}$ & $\begin{array}{l}\text { Alternati } \\
\quad \mathrm{f}\end{array}$ & $\begin{array}{l}\text { Kehadir } \\
\text { an/Absensi }\end{array}$ & $\begin{array}{l}\text { Perfor } \\
\text { ma } \\
\text { Kerja }\end{array}$ & $\begin{array}{c}\text { Jadwal } \\
\text { Pest } \\
\text { Control }\end{array}$ \\
\hline 1 & Toto & 0.9 & 1 & 0.9 \\
\hline 2 & Untung & 1 & 1 & 1 \\
\hline 3 & Wahyu & 0.8 & 0.875 & 0.8 \\
\hline 4 & Maman & 0.7 & 1 & 0.7 \\
\hline 5 & Asep & 0.9 & 0.875 & 0.9 \\
\hline
\end{tabular}

Dari penyelesaian perhitungan di atas, proses selanjutnya menggabungakannya kembali kedalam bentuk matriks,dapat dilihat pada Tabel 16.

Tabel. 16. Normalisasi Matriks

Sumber: Olah Data (2020)

\subsubsection{Menghitung nilai bobot preferensi pada setiap alternative}

Pada tahap ini adalah tahapan terakhir dari metode SAW (Simple Additive Weight). Dimana akan diproleh perangkingan dengan cara mengalikan bobot kriteria (w) dengan hasil matrik normalisasi (r), maka akan diperoleh nilai terbesar yang dipilih sebagai karyawan terbaik pada PT. Pestrap Mitra Sukses. Berikut perhitungannya:

$$
\begin{gathered}
V_{i}=\sum_{j=1}^{n} w_{j} r_{i} \mid \\
v 1=(0,9 * 0,655122655)+(1 * 0,211399711) \\
+(0,9 * 0,133477633) \\
=0,9211399702 \\
v 2=(0,1 * 0,655122655)+(1 * 0,211399711) \\
+(1 * 0,133477633) \\
=0,999999999 \\
v 3=(0,8 * 0,655122655)+(0,875 * 0,211399711) \\
+(0,8 * 0,133477633) \\
=0,815854973525 \\
\\
v 4=(0,7 * 0,655122655)+(1 * 0,211399711) \\
+(0,7 * 0,133477633) \\
=0,763419091 \\
\\
v 5=(0,9 * 0,655122655) \\
+(0,875 * 0,211399711)+(0,9 \\
* 0,133477633) \\
=0,894715001825
\end{gathered}
$$

Dari peritungan diatas dengan menggunakan metode SAW ( Simple Additive Weight) maka dapat disimpullkan bahwa nilai terbesar atau karyawan terbaik diperoleh oleh V2 yaitu Untung dengan nilai 0.999999999

\subsection{Hasil Pembahasan}

Dari hasil ahir perhitungan optimasi, dapat diambil kesimpulan bahwa alternatife yang bernama untung dengan nilai optimasi dengan metode AHP sebesar 0,3681 dan metode SAW sebesar 0,9999 merupakan nilai optimasi terbesar, yang menunjukan alternatife terpilih, sedangkan nilai optimasi terendah adalah yang bernama maman dengan optimasi menggunakan metode AHP sebesar 0,0713 dan metode SAW sebesar 0,7634. Hasil perhitungan diatas dengan menggunakan metode AHP dan SAW ditampilkan dalam bentuk grafik dibawah ini 


\section{Journal of Information System, Informatics and Computing}

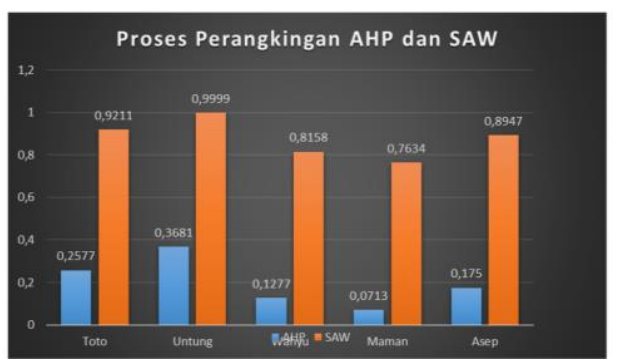

Sumber : Olah Data (2020)

Gambar 1. Grafik Perangkingan

Dari hasil yang didapat, maka dapat diambil kesimpulan bahwa metode AHP dan SAW dapat digunakan dalam pengambilan keputusan pemilihan karyawan terbaik pada PT.Pestrap Mitra Sukses yang berari $\mathrm{H} 1$ diterima dan $\mathrm{H} 0$ ditolak.pengaruh terhadap perhitungan dari kriteria dan alternatif menggunakan metode AHP dan SAW dalam menentukan karyawan terbaik di tahun 2020. Sedangkan, hipotesa H0 ditolak dengan dugaan tidak terdapat perbedaan antara perhitungan manual dengan perhitungan algoritma AHP dan SAW pada data perhitungan dari kriteria dan alternatif menggunakan metode AHP dan SAW dalam menentukan karyawan terbaik di tahun 2020, hipotesa tersebut tidak sesuai dengan yang telah diperkirakaan terhadap hasil yang telah didapatkan dari pengolahan dengan metode AHP dan SAW.

\section{KESIMPULAN}

Berdasarkan analisa yang telah dilakukan pada penelitian pada bab-bab sebelumnya, maka dapat diambil kesimpulan sebagai berikut:

1. Sistem pendukung keputusan yang dirancang mampu menentukan tingkat prioritas kepentingan setiap kriteria dalam penentuan karyawan terbaik pada PT. Pestrap Mitra Sukses.

2. Berdasarkan proses perhitungan dengan metode AHP dan SAW, telah menghasilkan keputusan dalam melakukan pemilihan karyawan terbaik guna mempermudah manager untuk menentukan hasil akhir.

3. Dalam penerapan metode Analitycal Hieararcy Proces (SAW) dan Simple Additive Wheigting (SAW) pada PT. Pestrap Mitra Sukses harus memenuhi empat kriteria yang diproses yaitu, data kehadiran, jadwal teknisi/karyawan melakukan pest control, performa kerja. Maka dengan melakukan perhitungan berhasil menentukan karyawan terbaik sesuai dengan kriteria dan bobot yang ditentukan semula sebelum perhitungan.

\subsection{Saran}

Dari hasil uraian penelitian yang telah dilakukan, maka saran yang dapat diajukan peneliti sebagai berikut:

1. Penelitian selanjutnya yang mungkin dapat kembangkan adalah menambah kriteria-kriteria dalam penentu keputusan karyawan terbaik pada sebuah instansi tertutama pada PT. Pestrap Mitra Sukses ini dalam divisi jadwal Pest control. Kami tidak membatasi jumlah kriteria yang ada kedepannya, karena hal tersebut bisa bertambah ataupun mengalami pengurangan atau perubahan lain. Projek menarik lainya adalah dapat mencoba menggabungkan metode-metode lain selain metode AHP dan SAW dalam penentu keputusan karyawan terbaik berdasarkan kebutuhan dan kebijakan yang ditetapkan pada PT.Pestrap Mitra Sukses.

2. Penilaian dilakukan secara berkala agar diperoleh informasi kinerja karyawan yang berkelanjutan dan dapat digunakan untuk peningkatan kualitas sumber daya manusia serta sebagai acuan untuk karyawan agar bekerja lebih giat guna memberikan hasil kinerja yang bagus dan berkualitas bagi perusahaan PT. Pestrap Mitra Sukses.

\section{REFERENASI}

Disusun dan diberi nomor urut berdasarkan urutan kutipan. Penulisan pustaka: nama penulis (tanpa gelar), tahun, judul, penerbit, dan kota penerbit. Berikut adalah contoh penulisan daftar pustak/referensi:

[1] C. Budihartanti, "Sistem Pendukung Keputusan Dalam Penilaian Karyawan Dengan Menerapkan Metode Simple Additive Weighting (SAW)," J. Inf. Syst. Applied, Manag. Account. Res. “JISAMAR, ” vol. 3, no. 3, pp. 1-10, 2019

[2] Frieyadie, "Metode AHP Sebagai Penunjang Keputusan Untuk Penilaian Kinerja Kerja Karyawan SPBU," J. TECHNO, vol. 15, no. 1, pp. 63-68, 2018.

JISICOM (Journal of Information System, Informatics and Computing)

http://journal.stmikjayakarta.ac.id/index.php/jisicom Telp.+62-21-3905050, e-mail:jisicom@stmikjayakarta.ac.id, jisicom2017@gmail.com 


\section{Journal of Information System, Informatics and Computing}

[3] Heny pratiwi, buku ajar sistem pendukung keputusan. 2016.

[4] D. Nofriansyah and S. Defit, Multi Criteria Decision Making (MCDM) Metode AHP," JISka, vol. 3, no. 2, pp. 119-125, 2018, doi: 10.33558/piksel.v6i2.1507.

[5] R. M. Munthe and A. S. RMS, "Sistem Pendukung Keputusan Pemilihan Karyawan Terbaik Dengan Metode AHP," JISka, vol. 3, no. 2, pp. 119-125, 2018, doi: 10.33558/piksel.v6i2.1507.

[6] Julinda Maya Paramudita, Verdi Yasin (2019) "Perancangan aplikasi sistem penyewaan alat berat (studi kasus: PT. Jaya Alam Sarana Jakarta)". Journal of Information System, Applied, Management, Accounting and Research.
e-ISSN: 2598-8719, p-ISSN: 2598-8700, Vol.3, No.1 (2019) http://journal.stmikjayakarta.ac.id/index.p hp/jisamar/article/view/73

[7] A. Darmawan and E. Purwaningsih, "Sistem Pendukung Keputusan Penilaian Kinerja Karyawan Dengan Metode Simple Additive Weighting Pada PT. Anggada Perkasa Teknik," Informatics Educ. Prof., vol. 4, no. 1, pp. 23-32, 2019, doi: 10.30591/jpit.v4i1.1034.

[8] A. A. Chamid dan B. Surarso, "Implementasi Metode AHP dan Promethee untuk Pemilihan Supplier," Jurnal Sistem Informasi Bisnis, vol. 2, 2015. 